\title{
OPTIMIZATION, KINETICS AND THERMODYNAMICS OF THE SOLID-LIQUID EXTRACTION PROCESS OF FLAVONOIDS FROM ROSEMARY (ROSEMARINUS OFFICINALIS) LEAVES
}

\author{
MILAN MITIĆa , SONJA JANKOVIĆa ${ }^{*}$, JELENA MRMOŠANIN ${ }^{a}$, \\ MILAN STOJKOVIĆa , DANIJELA KOSTIĆa, RUŽICA MICIĆ ${ }^{b}$
}

\begin{abstract}
Solid-liquid extraction of total flavonoids (TF) from rosemary (Rosemarinus officinalis) leaves was studied in the present work. The effects of type of solvent and its concentration, temperature and extraction time on amount of flavonoids as well as the effects of these parameters on the kinetics and thermodynamic parameters of extraction process were investigated. The effects of the process factors on the TF were assessed using the full factorial test plan $2^{3}$. Extraction using $50 \%$ ethanol in a $50{ }^{\circ} \mathrm{C}$ during $100 \mathrm{~min}$, was the most suitable conditions to produce a extract with high content of flavonoids (32.428 mg catechin equivalents / g rosemary leaves). The following twoparametric models were analyzed: non-stationary diffusion model trough the plant material, model of Ponomarev and parabolic diffusion model. All models gave a good fit to the experimental data (root mean square, RMS $<2 \%$, coefficient of determination, $\mathrm{R}^{2}>93 \%$ ). The $\Delta \mathrm{G}^{\circ}, \Delta \mathrm{S}^{\circ}$ and $\Delta \mathrm{H}^{\circ}$ values of the flavonoids extraction process were $-4.89-(-7.02) \mathrm{kJ} / \mathrm{mol}, 23.59-25.91 \mathrm{KJ} / \mathrm{mol}$ and $0.95-9.90 \mathrm{~kJ} / \mathrm{mol}$, respectively, indicating spontaneous, irreversible, and endothermic process.
\end{abstract}

Keywords: rosemary, flavonoids, kinetic model

\section{INTRODUCTION}

During the last few decades, consumption of the plants and their products is in constant growth. The continental climate in Serbia favours the growth of a great of number plant species, some of them have various

\footnotetext{
a Faculty of Sciences and Mathematics, Department of Chemistry, University of Niš, Višegradska 33, P.O. Box 224, 18000 Niš, Serbia

b Faculty of Science and Mathematics, Department of Chemistry, University of Priština

* Corresponding author: sonjajankovic1991@gmail.com
} 
medicinal and antioxidant properties [1,2]. Health benefits include antimicrobial and antioxidant efficacies, which can be of great significance in therapeutical approaches of many diseases [3].

Rosemarinus officinalis, commonly known as rosemary, is an shrub belonging to the Lamiaceae family. Native to the Mediterranean region, rosemary is now cultivated around the world due to its use as a natural food preservative and flavouring agent. Rosemary has also been used as a source of traditional medicine for centuries; its applications have ranged from memory enhancement to the treatment of gastrointestinal diseases [4, 5].

Formulations of rosemary include the raw leaves, and extracts of rosemary. Rosemary extract contains different classes of polyphenols including phenolic acids, flavonoids and phenolic terpenes. Phenolic acids include: the hydroxycinnamic acids, hydrobenzoic acids and hydroxyphenylacetic acids. Flavonoids include the flavones and flavonols $[6,7,8]$.

Extraction is the first step in the isolation of phenolic compounds from plant materials. Different techniques have been applied to recover antioxidant phenolic compounds from natural sources including solid/liquid extraction with organic solvent, microwave-assisted extraction, ultrasound-assisted extraction and supercritical fluid extraction. However, the efficiency of the extraction process is effected by several factors, such as the type of solvent and its concentration, the solvent/solid ratio, the number of extraction steps, $\mathrm{pH}$, time of contact, temperature and particle size of the solid matrix $[9,10]$. Thus, it is very important to optimize the extraction efficiency to each raw material. Also, mathematical modelling of solid-liquid extraction process is on important engineering tool in the design process in order to reduce energy, time and chemical reagents consumption.

The objectives of this study were to (1) evaluate the effect of type of solvent and its concentration, extraction temperature and extraction time on the flavonoids yield from rosemary, and then (2) investigate the kinetics and thermodynamics of the flavonoids extraction.

\section{RESULTS AND DISCUSSION}

\section{Optimization of extraction process}

The type of solvent and its concentration, extraction temperature and extraction time are key factors in extraction process, as they affect both kinetics and the extraction yield. Therefore, this study consisted in evaluating the effect of these variables, namely solvent concentration, extraction temperature and extraction time on the extraction process of flavonoids from rosemary leaves. The results obtained in these experiments shown significant changes in 
flavonoids content with different independent variables (supplementary materials Table 1S). By varying the extraction conditions, the flavonoid contents were increased about 5-fold in ethanol and about 3-fold in methanol solution. When comparing the maximum flavonoid content, the extraction in $50 \%$ ethanol seem the most successful. The efficiency of different solvents is related to the physicochemical properties of the flavonoid compounds (polarity, stability, solubility). The optimum extraction conditions were as follows: $50 \%$ ethanol, extraction temperature $50^{\circ} \mathrm{C}$, and extraction time 100 min.

A mathematical model was proposed for the extraction of flavonoids with ethanol and methanol as extraction solvent, The values of all linear regression coefficients for flavonoids extraction with ethanol and methanol are given in Table 2 .

The positive signs of the coefficients for extraction temperature and extraction time indicate a synergistic effect, while the negative sign for solvent concentration indicated an antagonistic effect.

The analysis of variance (ANOVA Test) for the response variables (content of flavonoids in ethanol and methanol solvent) are presented in Table 3S, Supplementary Material. The statistical significance of all three factors and their possible two- and three-way interaction for the flavonoids yields were evaluated for their $F$-and $p$-values. The statistical significance of a factor is greater if its $F$-value is higher. The value of $p<0.05$ indicates the significance of the factors and their interaction. The simplified regression equations are given in Table 6 . The predicted values of the flavonoids content are presented in Table 1S, Supplementary Material.

It was clear that the linear and interaction terms were highly significant $(p<0.05)$. The $F$-values for $x_{1}, x_{2}$ and $x_{3}$ factors are in interval 52.029-1658.4, respectively. The most important factor was the solvent concentration $\left(x_{1}\right)$, which was followed by the extraction temperature $\left(x_{2}\right)$ in cause extraction with ethanol, but in cause extraction with methanol followed by the extraction time $\left(x_{3}\right)$. On the two-ways interaction, it is worth to mention the combination of the solvent concentration and extraction time $\left(x_{1} x_{3}\right)$ affected flavonoids content in both solvents. The three-way interaction $\left(x_{1} x_{2} x_{3}\right)$ had no significant influence $(p>0.05)$ on the extraction yield of flavonoids. It is also necessary that the developed regression models (Table 3 ) provide an adequate approximation in real system. The regression analysis and ANOVA Test were used for fitting the models. The coefficients of determination $\left(R^{2}\right)$, the adjusted $R^{2}\left(R^{2}\right.$ adj $)$ and coefficient of variation (CV) were calculated to check the model adequacy (Table 3). Our results showed that the $R^{2}>98 \%$ and $R^{2}{ }_{a d j}>97 \%$, indicating that the regression model was suitable for explaining the behavior. Our results showed also that the coefficients of variation were $<5 \%$ for both the responses, representing a better precision and reliability of the conducted experiments. 
MILAN MITIĆ, SONJA JANKOVIĆ, JELENA MRMOŠANIN, MILAN STOJKOVIĆ,

DANIJELA KOSTIĆ, RUŽICA MICIĆ

\section{Kinetic analysis}

Since the data from previous experiment showed the highest influence of the solvent concentration and the temperature on the flavonoids content, different temperature $\left(T=30,40\right.$ and $\left.50^{\circ} \mathrm{C}\right)$ at extraction time intervals $(t=10$, $20,30,40,50,60,80$ and $100 \mathrm{~min}$ ) with pure ethanol, 50\% ethanol, pure methanol and $50 \%$ methanol were used the kinetic study. It is evident from Fig. 1 that flavonoids yield increase with temperature during the extraction process. This was due to increase in diffusion on the flavonoids and decrease in viscosity as the temperature. It is also evident from Fig. 1, the flavonoids content using $50 \%$ ethanol was higher when compared to the other solvents under to same conditions.

By analyzing the extraction curves for all extraction solvents used in this study, two periods of extraction were observed. A rapid increase in the content of flavonoids at the early beginning of the process and the slow increase in the content of total flavonoids, likely due to internal diffusion. The rapid extraction process at the beginning was due to free flavonoids on the surface of the plant material that was exposed to fresh solvent. In general, as seen in Fig. 1, most of the flavonoids are released from the rosemary leaves to the solvent during first 20 min of the extraction process.

In this work non-stationary diffusion model through the plant material, model of Ponomarev and parabolic diffusion model were used for description of flavonoids extraction process. The list of estimated kinetic parameters for all extraction solvent and all three analysed temperatures is given in Table 4. Kinetic parameters for non-stationary diffusion model, model of Ponomarev and parabolic diffusion model were obtained by plotting log $q / q_{\circ}$ and $\left(q_{0}-q\right) / q_{o}$ versus $\mathrm{t}$, and $\bar{q}$ versus $\mathrm{t}^{1 / 2}$, respectively.

As it can be seen their values were, more or less, dependent on the extraction conditions. It was observed that for all models, their kinetic parameters increased with increase in temperature. The flavonoids amount increase with temperature was due to the thermodynamic effect of flavonoids solubilization in the solid matrix particles [15]. A similar tendency was observed in previous studies where bioactive compounds were extracted from sage (Salvia officinalis L.) and glutinous sage (Salvia glutinosa L.) [13], from hop (Humulus lupulus L.) [18], and oil was extracted from Terminalia catappa [17] and from tabacco (Nicotiniatabacum L.) seeds [19].

When the ethanol concentration increased from 50 to $100 \%$ by volume, all kinetic parameters decreased, except $\mathrm{k}$, which increased. But, when methanol concentration increased from 50 to $100 \%$, diffusion extraction coefficients decreased, but washing coefficients increased. Also, the parabolic diffusion model predicts the smallest values of washing coefficients, while the same model predicts the highest values of diffusion extraction coefficients. 
Linear coefficient of determination $\left(R^{2}\right)$ and root mean square (RMS) were used to evaluate correlation between the experimental data and selected model. Table 3S, Supplementary Material presented of the $\mathrm{R}^{2}$ and RMS for each kinetic models and for all extraction conditions. From the results in Table 3S, Supplementary Material it was evident that irrespective of type solvent and their concentration, individual values of the RMS were less than $\pm 2 \%$ for each of the three models considered. It could be observed from Table 5 that while the average RMS decreased, the best fit of the models increased in the following order:

parabolic diffusion model $\rightarrow$ non-stationary diffusion model through the plant material $\rightarrow$ model of Ponomarev.

Similarly, the average linear correlation coefficient $R^{2}$ value increased in the following order:

parabolic diffusion model $\rightarrow$ non-stationary diffusion model through the plant material $\rightarrow$ model of Ponomarev

Based on these results, model of Ponomarev, having the highest value of the linear correlation coefficient $\mathrm{R}^{2}$, and lowest $\mathrm{RMS}$ values were chosen as the best extraction kinetics model for flavonoids extraction from rosemary leaves.

\section{Thermodynamic parameters}

The influence of temperature on extraction rate of flavonoids from rosemary was analysed using the Arrhenius equation (Eq.6). Calculated values of activation energies are given in Table 6 . The plot of Inb' (or k') (model of Ponomarev) vs. 1/T were used to determine the value of activation energies.

Calculated activation energies were in the range $2.38-13.22 \mathrm{~kJ} / \mathrm{mol}$. These values were in good agreement with literature values reported for other bioactive compounds [20,21, 22].

These results imply that the washing and diffusion coefficients were the most sensitive to temperature in the case of extraction with $100 \%$ methanol, and the least sensitive to temperature in case of extraction with $100 \%$ ethanol. Values of the activation energy are greater for the washing process than for the diffusion process, meaning that the former is stronger influenced by both extraction temperature and concentration of solvent than the latter process. The $E_{a}$-value for the flavonoids washing in $50 \%$ ethanol were higher 
than those in $100 \%$ ethanol, but those for $100 \%$ methanol were higher than those for the washing in $50 \%$ methanol. The $\mathrm{E}_{\mathrm{a}}$-value for the flavonoids' diffusion in 50 and $100 \%$ ethanol were similar to each other, and that for diffusion in $100 \%$ methanol was higher than those in $50 \%$ methanol.

Table 7 shows the values of equilibrium constants and thermodynamic parameters for the flavonoids extraction process from rosemary leaves. The plot of $\ln K_{e}$ vs. 1/T were used to determined the value of thermodynamic parameters. The values of enthalpy were the range of $1.07-2.26 \mathrm{~kJ} / \mathrm{mol}$. They increased with increase in the solvent concentration. Positive enthalpy change indicates the endothermic nature of the extraction process and as such required external energy source during the extraction [17, 23].

The entropy values for the extraction process were in the range of 23.59-25.91 $\mathrm{KJ} / \mathrm{mol}$. The positive value of entropy change describes the process is irreversible.

Similar results were obtained for extraction process for other compounds with different solvent [24, 25, 26, 27, 28].

The Gibbs free energy change values lie between -6.25 to $-6.93 \mathrm{~kJ} / \mathrm{mol}$ and -5.12 to $-7.02 \mathrm{~kJ} / \mathrm{mol}$, respectively for both types of extraction solvents. The Gibbs free energy change values for the extractions were all negative. Thus, indicating that the process was feasible and spontaneous.

The efficiency of the flavonoids extraction was favoured with increasing extraction temperature. A similar tendency was also reported for flavonoids extraction from Phyllanthus emblica (-2.65 to $0.15 \mathrm{~kJ} / \mathrm{mol})$ [24], total phenolics from hop (-11.99 to $-10.78 \mathrm{~kJ} / \mathrm{mol})$ [22], coconut oil $(-1.16$ to $-0.12 \mathrm{~kJ} / \mathrm{mol})$ [23], olive cake oil (-6.25 to $-4.45 \mathrm{~kJ} / \mathrm{mol})[26]$, and hempseeds oil $(-5.17$ to $-2.41 \mathrm{~kJ} / \mathrm{mol})$ [28].

a)

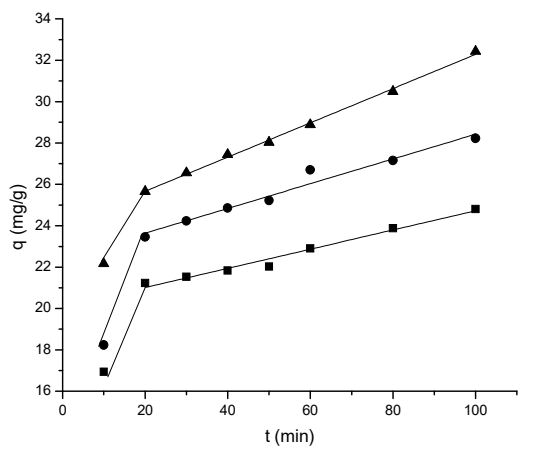

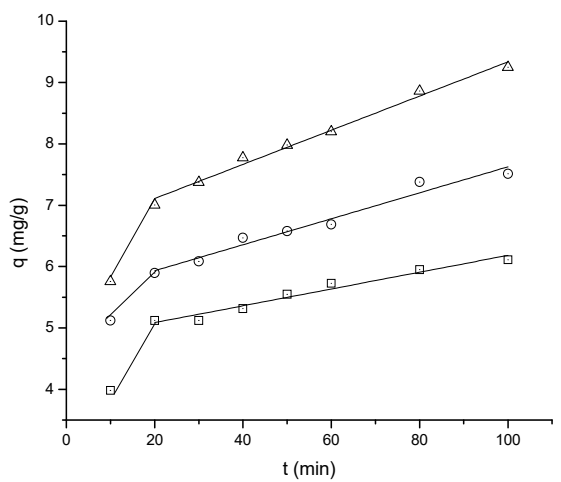


b)

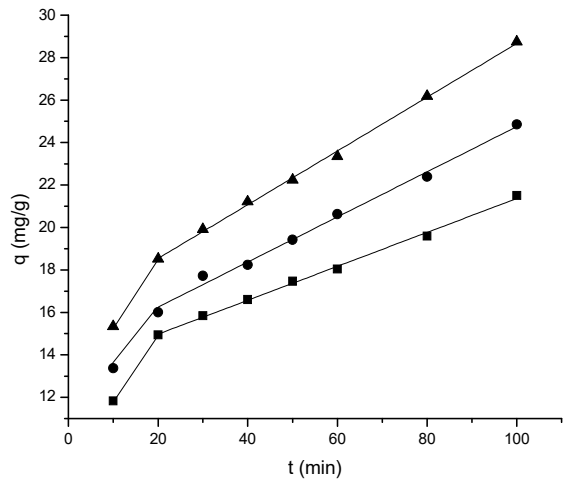

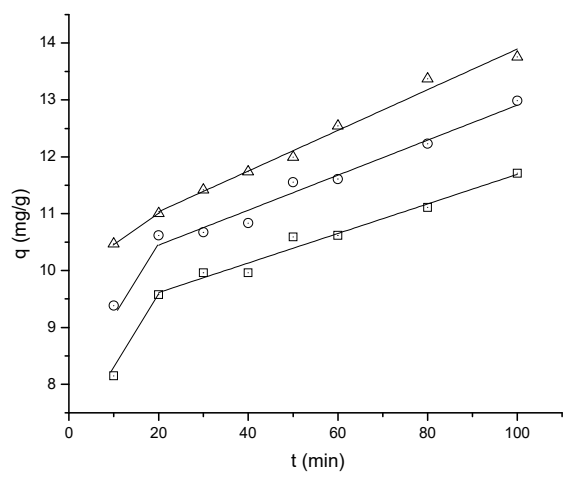

Figure 1. Effect of the extraction time on the total flavonoids yield in a) ethanol and b) methanol extraction solvent at different solvent concentration: $50 \%$ at $\boldsymbol{\Delta}-30{ }^{\circ} \mathrm{C}$, - $-40{ }^{\circ} \mathrm{C}$ and $-50^{\circ} \mathrm{C} ; 100 \%$ at $\Delta-30^{\circ} \mathrm{C}, \circ-40{ }^{\circ} \mathrm{C}$ and $\square-50{ }^{\circ} \mathrm{C}$

Table 1. Parameters and levels using in the $2^{3}$ factorial design study

\begin{tabular}{|lcc|}
\hline Parameters & $(-1)$ & Levels \\
& 50 & $(+1)$ \\
\hline Solvent concentration ${ }^{\mathrm{a}}, \%\left(\mathrm{x}_{1}\right)$ & 30 & 100 \\
Extraction temperature, ${ }^{\circ} \mathrm{C}\left(\mathrm{x}_{2}\right)$ & 20 & 50 \\
Extraction time, min $\left(\mathrm{x}_{3}\right)$ & Maceration & 10 \\
Extraction method & \\
\hline
\end{tabular}

Table 2. Regression coefficient of the predicted linear first-order models

\begin{tabular}{|c|c|c|}
\hline Model parameters & $\begin{array}{c}\text { Regression } \\
\mathrm{TF}, \mathrm{mg} g \text { in ethanol }\end{array}$ & $\begin{array}{c}\text { Coefficients } \\
\mathrm{TF}, \mathrm{mg} \mathrm{g} \text { in methanol }\end{array}$ \\
\hline Intercept & 16.451 & 16.221 \\
Linear & -9.578 & -4.709 \\
$\mathrm{x}_{1}$ - solvent concentration & 2.133 & 1.788 \\
$\mathrm{x}_{2}$ - temperature & 1.696 & 2.709 \\
$\mathrm{x}_{3}-$ time & -0.879 & -0.920 \\
Interaction & -0.889 & -1.488 \\
$\mathrm{x}_{1} \mathrm{x}_{2}$ & 0.556 & 0.533 \\
$\mathrm{x}_{1} \mathrm{x}_{3}$ & -0.244 & -0.380 \\
$\mathrm{x}_{2} \mathrm{x}_{3}$ & \\
$\mathrm{x}_{1} \mathrm{x}_{2} \mathrm{x}_{3}$ & & \\
\hline
\end{tabular}

Table 3. Regression equations

\begin{tabular}{|c|c|c|c|c|}
\hline \begin{tabular}{|l|} 
Solvent \\
\end{tabular} & & $\mathrm{CV}(\%)$ & $\operatorname{Radj}^{2}(\%)$ & $\mathrm{R}^{2}(\%)$ \\
\hline Ethanol & $\begin{array}{l}y=16.451-9.578 x_{1}+2.133 x_{2}+1.696 x_{3}-0.879 x_{1} x_{2}- \\
0.889 x_{1} x_{3}+0.556 x_{2} x_{3}\end{array}$ & 4.04 & 99.23 & 99.59 \\
\hline Methanol & $\begin{array}{l}y=16.221-4.709 x_{1}+1.788 x_{2}+2.709 x_{3}-0.920 x_{1} x_{2}- \\
1.488 x_{1} x_{3}+0.533 x_{2} x_{3}\end{array}$ & 3.99 & 97.85 & 98.85 \\
\hline
\end{tabular}


MILAN MITIĆ, SONJA JANKOVIĆ, JELENA MRMOŠANIN, MILAN STOJKOVIĆ,

DANIJELA KOSTIĆ, RUŽICA MICIĆ

Table 4. Values of estimated model parameters for solid/liquid extraction for total flavonoids from rosemary leaves

\begin{tabular}{|c|c|c|c|c|c|}
\hline Solvent & $\mathrm{T}$ & & Model & $\mathrm{A}$ & \\
\hline \multirow{2}{*}{$100 \%$ ethanol } & $\left({ }^{\circ} \mathrm{C}\right)$ & $\mathrm{b}$ & $\mathrm{k}$ & $\mathrm{RMS}$ & $\mathrm{R}^{2}$ \\
& 30 & 0.741 & $1.038 \cdot 10^{-3}$ & 1.33 & 95.64 \\
& 40 & 0.775 & $1.365 \cdot 10^{-3}$ & 1.56 & 96.11 \\
& 50 & 0.811 & $1.478 \cdot 10^{-3}$ & 1.24 & 98.10 \\
$50 \%$ ethanol & 30 & 0.823 & $0.885 \cdot 10^{-3}$ & 0.72 & 98.37 \\
& 40 & 0.842 & $1.013 \cdot 10^{-3}$ & 1.18 & 96.10 \\
& 50 & 0.851 & $1.245 \cdot 10^{-3}$ & 0.32 & 99.83 \\
& & & & & \\
$100 \%$ methanol & 30 & 0.822 & $1.070 \cdot 10^{-3}$ & 1.09 & 97.31 \\
& 40 & 0.835 & $1.148 \cdot 10^{-3}$ & 1.19 & 97.30 \\
& 50 & 0.844 & $1.252 \cdot 10^{-3}$ & 0.93 & 98.31 \\
& & & & & \\
$50 \%$ methanol & 30 & 0.771 & $1.923 \cdot 10^{-3}$ & 0.71 & 99.68 \\
& 40 & 0.786 & $2.276 \cdot 10^{-3}$ & 1.55 & 99.02 \\
& 50 & 0.806 & $2.586 \cdot 10^{-3}$ & 1.78 & 98.66 \\
\hline
\end{tabular}

The continuation of Table 4

\begin{tabular}{|c|c|c|c|c|c|c|c|}
\hline 2 & Model & $\mathrm{B}$ & & & Model & $\mathrm{C}$ & \\
\hline $\mathrm{b}^{\prime}$ & $\mathrm{k}^{\prime}$ & $\mathrm{RMS}$ & $\mathrm{R}^{2}$ & $\mathrm{~A}_{\circ}$ & $\mathrm{A}_{1}$ & $\mathrm{RMS}$ & $\mathrm{R}^{2}$ \\
\hline 0.382 & $1.095 \cdot 10^{-3}$ & 1.24 & 96.18 & 0.325 & $16.306 \cdot 10^{-3}$ & 1.26 & 96.86 \\
0.437 & $1.685 \cdot 10^{-3}$ & 1.42 & 96.96 & 0.353 & $24.604 \cdot 10^{-3}$ & 1.43 & 96.87 \\
0.521 & $2.212 \cdot 10^{-3}$ & 0.94 & 98.94 & 0.409 & $32.363 \cdot 10^{-3}$ & 0.70 & 96.79 \\
& & & & & & & \\
0.562 & $1.296 \cdot 10^{-3}$ & 0.80 & 97.88 & 0.500 & $18.571 \cdot 10^{-3}$ & 1.14 & 94.67 \\
0.628 & $1.677 \cdot 10^{-3}$ & 1.08 & 96.66 & 0.543 & $24.580 \cdot 10^{-3}$ & 0.93 & 97.56 \\
0.672 & $2.324 \cdot 10^{-3}$ & 0.37 & 99.75 & 0.557 & $33.640 \cdot 10^{-3}$ & 1.08 & 97.91 \\
& & & & & & & \\
0.557 & $1.597 \cdot 10^{-3}$ & 1.06 & 97.43 & 0.478 & $23.184 \cdot 10^{-3}$ & 1.21 & 96.64 \\
0.602 & $1.890 \cdot 10^{-3}$ & 1.26 & 96.99 & 0.511 & $27.179 \cdot 10^{-3}$ & 1.75 & 93.83 \\
0.632 & $2.192 \cdot 10^{-3}$ & 0.77 & 98.75 & 0.523 & $31.920 \cdot 10^{-3}$ & 1.01 & 98.20 \\
& & & & & & & \\
0.423 & $2.520 \cdot 10^{-3}$ & 0.56 & 99.74 & 0.280 & $36.536 \cdot 10^{-3}$ & 1.51 & 98.19 \\
0.446 & $3.356 \cdot 10^{-3}$ & 1.19 & 99.38 & 0.298 & $28.370 \cdot 10^{-3}$ & 1.78 & 98.14 \\
0.506 & $3.997 \cdot 10^{-3}$ & 0.57 & 99.85 & 0.309 & $57.860 \cdot 10^{-3}$ & 1.95 & 98.18 \\
\hline
\end{tabular}


OPTIMIZATION, KINETICS AND THERMODYNAMICS OF THE SOLID-LIQUID EXTRACTION PROCESS OF FLAVONOIDS FROM ROSEMARY (ROSEMARINUS OFFICINALIS) LEAVES

Table 5. Comparison of the average percentage RMS and $\mathrm{R}^{2}$ for different kinetic models

\begin{tabular}{|c|c|c|c|c|c|c|c|c|}
\hline $\begin{array}{c}\text { Kinetic } \\
\text { model }\end{array}$ & $\begin{array}{c}100 \% \\
\mathrm{RMS}\end{array}$ & $\begin{array}{c}\text { Ethanol } \\
\mathrm{R}^{2}\end{array}$ & $\begin{array}{c}50 \% \\
\mathrm{RMS}\end{array}$ & $\begin{array}{c}\text { Ethanol } \\
\mathrm{R}^{2}\end{array}$ & $\begin{array}{c}100 \% \\
\mathrm{RMS}\end{array}$ & $\begin{array}{c}\text { Methanol } \\
\mathrm{R}^{2}\end{array}$ & $\begin{array}{c}50 \% \\
\mathrm{RMS}\end{array}$ & $\begin{array}{c}\text { Methanol } \\
\mathrm{R}^{2}\end{array}$ \\
\hline Model A & 1.37 & 96.62 & 0.75 & 98.09 & 1.07 & 97.64 & 1.35 & 99.14 \\
Model B & 1.20 & 97.36 & 0.74 & 98.10 & 1.03 & 97.72 & 0.77 & 99.66 \\
Model C & 1.30 & 96.84 & 1.05 & 98.72 & 1.32 & 96.23 & 1.75 & 98.17 \\
\hline
\end{tabular}

Table 6. Activation energy $(\mathrm{kJ} / \mathrm{mol})$ at different extraction solvent

\begin{tabular}{|c|c|c|c|c|}
\hline Process & $100 \%$ ethanol & $50 \%$ ethanol & $100 \%$ methanol & $50 \%$ methanol \\
\hline Washing & 5.43 & 9.33 & 13.22 & 8.93 \\
Diffusion & 2.38 & 2.71 & 5.35 & 3.61 \\
\hline
\end{tabular}

Table 7. Thermodynamic parameters of the flavonoids' extraction process with different solvents

\begin{tabular}{|c|c|c|c|c|c|}
\hline Solvent & $\begin{array}{c}\mathrm{T} \\
\left({ }^{\circ} \mathrm{C}\right)\end{array}$ & $K_{e}$ & $\begin{array}{c}\Delta H^{o} \\
(\mathrm{~kJ} / \mathrm{mol})\end{array}$ & $\Delta S^{o}(\mathrm{JK} / \mathrm{mol})$ & $\Delta G^{o}(\mathrm{~kJ} / \mathrm{mol})$ \\
\hline $100 \%$ ethanol & 30 & 0.945 & 1.601 & 25.906 & -6.248 \\
& 40 & 1.482 & & & -6.507 \\
& 50 & 2.701 & & & -6.766 \\
$50 \%$ ethanol & 30 & 2.271 & 1.117 & 24.929 & -6.437 \\
& 40 & 3.764 & & & -6.686 \\
& 50 & 9.841 & & & -6.935 \\
& & & & & -4.888 \\
& 30 & 2.543 & 2.259 & 23.588 & -5.124 \\
& 40 & 3.896 & & & -5.360 \\
& 50 & 5.366 & & & -6.519 \\
& & & & & -6.769 \\
& 30 & 2.119 & 1.067 & & -7.020 \\
\hline
\end{tabular}


MILAN MITIĆ, SONJA JANKOVIĆ, JELENA MRMOŠANIN, MILAN STOJKOVIĆ,

DANIJELA KOSTIĆ, RUŽICA MICIĆ

\section{CONCLUSIONS}

A full factorial experiment $2^{3}$ was used to determine the optimum parameters that gave high extraction yields. The analysis of variance showed that the effects of all variables (solvent concentration, extraction temperature and extraction time) were extremely significant. The linear regression mathematical models had higher correlation and could be employed to optimize the flavonoids extraction from rosemary leaves. Results from this study suggested that $50 \%$ ethanol was the best solvent for the extraction of flavonoids from rosemary leaves since it give the highest flavonoids yield compared to the other solvents (pure ethanol, pure methanol, $50 \%$ methanol) examined. The three kinetic models describe: non-stationary diffusion model through the plant material, model of Ponomarev and parabolic diffusion model all reasonably described flavonoids extraction from rosemary leaves as indicated by high $\mathrm{R}^{2}$ and low RMS values. Model of Ponomarev gave the best fit followed by non-stationary diffusion model, and then parabolic diffusion model. The $\Delta \mathrm{H}^{\circ}, \Delta \mathrm{S}^{\circ}$, and $\Delta \mathrm{G}^{\circ}$ values obtained for the four different extraction solvents indicated that the extraction process was spontaneous, irreversible, and endothermic, respectively.

\section{EXPERIMENTAL}

\section{Plant materials}

Rosemary (Rosemarinus officinalis) leaves was collected in B. Palanka area (Republic of Serbia) during the flowering season of 2018 and dried naturally in the shade for one month. Dried plant material was grounded in the blender (average plant particle size: $0.60 \mathrm{~mm}$ ) and kept the paper bags before its usage.

\section{Solvent and chemicals}

\section{Extraction procedure and experimental design}

In the first stage, the extraction experiments were performed using different conditions of solvent concentration (ethanol or methanol), extraction temperature and extraction time. The conditions used in each experiment were settled according to the $2^{3}$ full factorial design presented in Table 1. The maceration procedure was employed for the extraction of flavonoids from rosemary leaves. Thus, according to the experimental design (Table 1S, 
Supplementary Material), plant samples (2g) were extracted by a same volume but different solvent concentration, at a different temperature and a different extraction time. The extraction process was carried out using a bath thermostate. After each extraction, extract filtered on Whatman filter paper (No.1) and evaporated to dryness using a rotary evaporator (BUCHI rotavapor R-200). Dried extract was dissolved in extraction solvent before analysis. For each extraction solvent (experimental design), the response function investigated was $y=\mathrm{mg}$ of flavonoid $/ \mathrm{g}$ of dry plant material $(\mathrm{mg} / \mathrm{g})$. Regression analysis was performed based on the experimental data and was fitted into a proposed linear first-order model using the following equation [11]:

$$
y=\beta_{o}+\sum_{i=1}^{k} \beta_{i} x_{i}+\sum_{i=1}^{k-1} \sum_{j=2}^{k} \beta_{i j} x_{i} x_{j}+\sum_{i=1}^{k-2} \sum_{j=2}^{k-1} \sum_{k=3} \beta_{i j k} x_{i} x_{j} x_{k}
$$

Where $y$ is the flavonoids content (response), $x_{i}$ the independent variables influencing the responses, $\beta_{o}, \beta_{i}, \beta_{i j}, \beta_{i j k}(i, j, k=1,2,3)$ are the regression coefficients of variables for intercept, linear and 2- and 3-factor interaction terms, respectively. The quality of the fit of the regression model was expressed by the adjusted R-squared (adjusted $R^{2}$ ), coefficient of determination $\left(R^{2}\right)$ and coefficient of variation $(C V)$.

\section{Initial content of flavonoids}

Macerated plant material $(2 \mathrm{~g})$ was weighed into a $250 \mathrm{~mL}$ Erlenmeyer flask with a ground stopper and covered with $50 \mathrm{ml}$ of the extraction solvent. The extraction was carried out by the maceration method for a period of 100 minutes. The extracts were separated from the residues by filtering through the Whatman No. 1 filter paper. The residues were extracted twice with the same fresh solvent and extracts combined. The combined extracts were concentrated and freed of solvent under reduced pressure at $45^{\circ} \mathrm{C}$, using a rotary evaporator (BUCHI Rotavapor R-200). The dried crude concentrated extracts were dissolved using extraction solvent until used for analysis. The dried extracts were prepared thrice and the results averaged. The values of the initial contents of flavonoids in rosemary were $12.583,35.723,16.318$ and $31.653 \mathrm{mg} / \mathrm{gdw}$ in $100 \%$ ethanol, $50 \%$ ethanol, $100 \%$ methanol and $50 \%$ methanol, respectively.

\section{Determination of total flavonoids}

Total flavonoids were determined using previously described spectrophotometric method [12]. The results for total flavonoids were expressed as milligrams of catechin equivalents per $\mathrm{g}$ of dry rosemary leaves $(\mathrm{mg} \mathrm{CE} / \mathrm{g})$. 
MILAN MITIĆ, SONJA JANKOVIĆ, JELENA MRMOŠANIN, MILAN STOJKOVIĆ,

DANIJELA KOSTIĆ, RUŽICA MICIĆ

\section{Kinetics of flavonoids extraction}

The rosemary leaves $(2 \mathrm{~g})$ and the extraction solvent $(50 \mathrm{~mL})$ were placed in a series of Erlenmayer flasks $(250 \mathrm{~mL}$ ) and the flasks were macerated in $10,20,30,40,50,60,80$ and 100 minutes. The temperature was controlled and maintained at $30 \pm 0.1^{\circ} \mathrm{C}$. After each time interval the liquid extract was separated from the plant material residues by vacuum filtration. Liquid extracts were prepared thrice and the results averaged. The procedure was repeated at $40 \pm 0.1^{\circ} \mathrm{C}$ and $50 \pm 0.1^{\circ} \mathrm{C}$.

\section{Modelling of flavonoids extraction kinetics}

The extraction kinetics flavonoids from rosemary was modelled by three models (Table 2S, Supplementary Material): non-stationary diffusion model through the plant material, model of Ponomarev [13] and parabolic diffusion model [14].

\section{Thermodynamic parameters}

Influence of temperature on the extraction rate was assessed using Arrhenius equation:

$$
k=A e^{-E_{a} / R T}
$$

where $k$ represent the extraction rate, $A$ is the Arrhenius constant, $E_{a}$ is the activation energy, $R$ is the universal gas constant, and $T$ is the absolute temperature. A plot of $\operatorname{lnk}$ versus $1 / T$ gives a straight slope where $-E_{a} / R$ represents the activation energy of the extraction process [3].

Thermodynamic parameters $\left(\Delta \mathrm{G}^{\circ}, \Delta \mathrm{H}^{\circ}, \Delta \mathrm{S}^{\circ}\right)$ were estimated using Eqs.(3)- (5):

$$
\begin{aligned}
& \Delta G^{o}=-R T \ln K_{e} \\
& \ln K_{e}=-\frac{\Delta G^{o}}{R T}=-\frac{\Delta H^{o}}{R T}+\frac{\Delta S^{o}}{R} \\
& K_{e}=\frac{q_{L}}{q_{S}}
\end{aligned}
$$

where $K_{e}$ is equilibrium constant, $q_{L}$ is amount of flavonoids in liquid at equilibrium temperature $\mathrm{T}, q_{S}$ is amount of flavonoids in solid at equilibrium temperature, while $\Delta H^{o}(\mathrm{~kJ} / \mathrm{mol}), \Delta S^{o}(\mathrm{JK} / \mathrm{mol})$, and $\Delta G^{o}(\mathrm{~kJ} / \mathrm{mol})$ are enthalpy change, entropy change and Gibbs free energy change, respectively [15]. 
OPTIMIZATION, KINETICS AND THERMODYNAMICS OF THE SOLID-LIQUID EXTRACTION PROCESS OF FLAVONOIDS FROM ROSEMARY (ROSEMARINUS OFFICINALIS) LEAVES

\section{Statistical analysis}

A full factorial model $2^{3}$ with replication was used to optimize the flavonoids extraction with respect to type of solvent and its concentration, extraction temperature and extraction time, the factors affecting flavonoids yields. The significance of the factors and their combinations were evaluated by the ANOVA Test using a computer program. The linear first-order regression equations were also developed to show the dependence of flavonoids yields on factors and their interactions.

The best fit among the models was evaluate using coefficient of determination $\left(R^{2}\right)[16]$ and root mean square (RMS) [14, 17].

The higher the value of $\mathrm{R}^{2}$ and lower the values of the RMS; the better will be goodness of the fit [14].

SUPPLEMENTARY MATERIALS can be obtained by request from the authors.

\section{ACKNOWLEDGMENTS}

Research in this paper is part of the project "Functional analysis, stochastic analysis and applications" no. 174007 financed by the Ministry of Education, Science and Technological Development of the Republic of Serbia.

\section{REFERENCES}

1. P. Mašković; V. Veličković; S. Đurović; Z. Zeković; M. Radojković; A. Cvetanović; J. Švarc-Gajić; M. Mitić; J.Vujić; Phytomedicine, 2018, 38, 118-124.2. A. Žugić; S. Đorđević; I. Arsić; G. Marković; J. Živković; S. Jovanović; V. Tadić; Ind. Crop Prod., 2014, 52, 519-527.

3. A. J. Tušek; M. Benković; A. Belščak Cvitanović; D.Valinger; Ind. Crop Prod., 2016, 91, 205-214.

4. H. Rafi; H. Soheila; E. Grant; Herbal Medicine, 2017, 3, 2-8.

5. S. Selmi; K. Rtibi; D. Grami; H. Sebai; L.Marzonki; Pathophysiology, 2017, 24, 297-303.

6. M. B. Hassain; D. K. Rai; N. P. Brunton; A. B. Maktin-Diana; C. Barry-Ryan; J. Agric. Food Chem., 2010, 58, 10576-10581.

7. A. Valverdu-Queralt; J. Regueiro; M. Martinez-Huelamo; J. F. Rinaldi Avarega; L. N. Leal; M. R.Lamuela-Raventos; Food Chem., 2014, 154, $299-307$.

8. P. Mena; M. Cirtina; K. A. Herrlinger; C. Dall'Asta; D. Del Rio; Molecules, 2016, 21, 1576.

9. M. T. Escribano-Bailon; C. Santos-Buelga; Methods in Polyphenol Analysis; Polyphenol extraction from foods, In: C. Santos-Buelga, G. Williamson (Eds.), The Royal Society of Chemistry: Cambridge, United Kingdom, 2003; pp. 1-16. 
MILAN MITIĆ, SONJA JANKOVIĆ, JELENA MRMOŠANIN, MILAN STOJKOVIĆ,

DANIJELA KOSTIĆ, RUŽICA MICIĆ

10. S. I. Mussato; L. F. Ballesteros; S. Martins; J. A. Teixeira; Sep. Sci. Technol., 2011, 83, 173-179.

11. M. A. Bezerra; R. E. Santelli; E. P. Oliveira; L. S. Villar; L. A. Escaleira; Talanta, 2008, 76, 965-977.

12. B. T. Stojanović; S. S. Mitić; G. S. Stojanović; M. N. Mitić; D. A. Kostić; D.Đ. Paunović; B. B. Arsić; A. N. Pavlović; Food Chem., 2017, 232, 466-475.

13. D. T. Veličković; D. M. Milenović; M. S. Ristić; V. B. Veljković; Ultrason. Sonochem., 2006, 13, 150-156.

14. S. Kitanović; D. Milenović; V. Veljković; Biochem. Eng. J., 2008, 41, 1-11.

15. M. Y. Liauw; F. A. Natan; F. A. Widiyanti; D. Ikasari; N. Indraswati; F. E. Soetaredjo; ARPN J. Eng. Appl. Sci., 2008, 3(3), 1-6.

16. R. C. A. Amarante; P. M. Oliveria; F. K. Schwantes; J. A. Morón-Villareyes; Ind. Eng. Chem. Res., 2014, 53, 16, 6824-6829.

17 M. C. Menkiti; C. M. Agu; T. K. Udeigwe; Ind. Crop Prod., 2015, 77, 713-723.

18. D. Đ.Paunović; S. S. Mitić; D. A. Kostić; M. N. Mitić; B. T. Stojanović, J. Lj. Pavlović; Adv. Technol., 2014, 3, 58-63.

19. I. T. Stanisavljević; M. L. Lazić; V. B. Veljković; Ultrason.Sonochem., 2007, 14, 646-652.

20. A. Bucić-Kojić; M. Planinić; S. Tomas; M. Bilić; D. Velić; J. Food Eng., 2007, 81, 236-242.

21. V. Sant'Anna; A. Brandelli; L. D. F. Marczak; I. C. Ressaro; Sep. Pur. Thechnol., 2012, 100, 82-87.

22. D. Đ.Paunović; S. S. Mitić; G. S. Stojanović; M. N. Mitić; B. T. Stojanović; M. B. Stojković; Sep. Sci. Technol., 2015, 50, 1658-1664.

23. S. Sulaiman; A. R. Abdul Aziz; M. K. Aroua; J. Food Eng., 2013, 114, 228-234.

24. R. Y. Krishnan; K. S. Rajan; Braz. J. Chem. Eng., 2017, 34, 885-899.

25. S. Amin; S. Hawash; G. El Diwani; S. El Rafei; Am. J. Sci., 2010, 6, 8.

26. S. Meziane; H. Kadi; J. Am. Oil Chem. Soc., 2008, 85, 391-396.

27. H. Topolar; U.Gecgel; Turk. J. Chem., 2000, 24, 247-253.

28. M. D. Kostić; N. M. Joković; O. S. Stamenković; K. M. Rajković; P. S. Milić; V. B.Veljković; Ind. Crop Prod., 2014, 52, 679-686. 